\title{
B. Situación en Libia, Caso de la Fiscalía c. Saif Al Islam Gaddafi y Abdullah Al-Senussi
}

Análisis de la decisión sobre la apelación de Abdullah Al-Senussi frente a la decisión de la Sala de Cuestiones Preliminares I, del 11 de octubre de 2013, denominada "Decisión sobre la admisibilidad del caso en contra de Abdullah Al-Senussi"*

Paula Viviana Fierro Barreto ${ }^{* *}$

\section{Antecedentes}

El 24 de junio de 2014, la Sala de Apelaciones (en adelante, Sala) de la Corte Penal Internacional (en adelante, CPI o Corte) confirmó la decisión que declaró la inadmisibilidad del caso en contra de Abdullah Al-Senussi, en la situación de Libia, emitida el 11 de octubre de 2013 por la Sala de Cuestiones Preliminares I (en adelante, SCP I). El señor Al-Senussi estaba siendo investigado como autor mediato, a luz del Artículo 25.3.a del Estatuto de Roma (en adelante, ER), por la comisión de asesinatos y acto de persecución como crímenes de lesa humanidad presuntamente ocurridos entre el 15 de febrero y, al menos, hasta el 20 de febrero de 2011, con ocasión de la represión a los opositores del régimen de Muammar Gaddafi en Bengasi. Respecto a la misma situación de Libia, en el año 2013 la SCP I se había pronunciado sobre la admisibilidad del caso en contra de Saif Al Islam Gaddafi.

* CORTE PENAL INTERNACIONAL, Situación en Libia, caso de la Fiscalía contra Saif Al Islam Gaddafi y Al-Senussi, “Decisión sobre la admisibilidad del caso en contra de Abdullah Al-Senussi”, [En línea], 24 de julio 2014. Disponible en <http://www.icc-cpi.int/iccdocs/doc/doc1807073.pdf> [Consulta: 03.03.2015].

** Estudiante de la Facultad de Jurisprudencia de la Universidad del Rosario. Correo electrónico: fierro. paula@urosario.edu.co 
La SCP I declaró inadmisible el caso en contra del señor Al-Senussi, con base en el análisis de admisibilidad del Artículo 17 del ER. La Sala aplicó el test del "mismo caso", decantado en su decisión del 24 de febrero de 2006 en el caso de Thomas Lubanga Dyilo. ${ }^{1}$ Dicho test tiene dos componentes: i) el mismo sujeto, y ii) la misma conducta. En cuanto al segundo componente, la Sala reiteró lo que había establecido en la decisión de admisibilidad de Gaddafi sobre el estándar de prueba consistente en "un grado suficiente claro y específico para probar".

En la decisión de Al-Senussi, la SCP I constató que, conforme a la evidencia aportada por el Estado, las autoridades competentes de Libia estaban tomando medidas concretas y progresivas en relación con la responsabilidad penal del señor Al-Senussi por la "misma conducta" investigada por la Corte. ${ }^{3}$ Tras determinar esta primera parte del test, la Sala procedió a establecer si el Estado tenía la disposición y la capacidad para llevar a cabo el procedimiento; cualquiera de los dos escenarios era suficiente para declarar admisible el caso. La SCP I concluyó que Libia tenía disposición, debido a que la investigación se había adelantado de manera adecuada y que los problemas relativos a la representación legal del acusado no implicaban una falta de voluntad del Estado. Por otro lado, la capacidad de aprehender y tener bajo custodia de autoridades libias al señor Al-Senussi, de obtener evidencia y testimonios y de aplicar los procedimientos pese a la situación de seguridad que afrontaba Libia, demostraban la capacidad del Estado en los términos del Artículo 17 ER.

\section{Decisión de apelación}

La defensa de Al-Senussi apeló la decisión de primera instancia en la que se declaró la inadmisibilidad del caso. La apelación se basó en tres alegatos que fueron objeto de análisis por la Sala, como se refiere a continuación.

En primer término, la Sala se refirió a la solicitud de apreciar pruebas adicionales no disponibles previamente y que, de acuerdo con la defensa, demostraban la falta de disposición y de capacidad de Libia para ejecutar los procedimientos en contra de Al-Senussi. La Sala retomó lo dicho en la decisión sobre la apelación de la decisión de admisibilidad del caso de Gaddafi ${ }^{4}$ y dejó claro que no consideraría documentos que no hubieran sido presentados ante la Sala de Cuestiones Preliminares en la respectiva etapa.

1 CORTE PEnAl INTERnACIONAL, Sala de Cuestiones Preliminares I, "Situation in the Democratic Republic of the Congo in the Case of the Prosecutor vs. Thomas Lubanga, párr. 31. CORTE PENAL INTERNACIONAL, Sala de Cuestiones Preliminares I, párr. 66 (VI). Ibid., párr. 167.

SALA APELACIONES, Prosecutor us. Saif Al-Islam Gaddafi and Abdullah Al-Senussi, Decisión sobre la apelación de Libia en contra de la decisión de la Sala de Cuestiones Preliminares del 31 de mayo de 2013 titulada "Decisión en la admisibilidad del caso en contra de Saif Al-Islam Gaddaf", 24 de mayo de 2014, ICC-01/11-01/11-547-Red, párr. 43. 
En segunda medida, la Sala abordó la petición de la defensa respecto al alegado error en el que incurrió la SCP I, al concluir que Libia estaba haciendo una investigación en el "mismo caso" presentado ante la Corte. La Sala comenzó su análisis subrayando que no es necesario analizar cada uno de los "incidentes" o "eventos" para establecer que se trata de un "mismo caso", si bien estos pueden constituir un indicador relevante para afirmar la existencia de un "mismo caso". A continuación procedió a revisar los "incidentes" o "eventos" de las conductas investigadas por el Estado, para afirmar que tenían similitud con aquellos llevados ante la Corte, lo que permitió concluir que se trataba de un "mismo caso". Además, indicó que, a pesar de que no existe un crimen de "persecución" en el Código Penal libio, hay disposiciones que cubren sustancialmente la misma conducta.

En tercer lugar, la Sala abordó las alegaciones de la defensa sobre los posibles errores de hecho y de Derecho en los que podía haber incurrido la SCP al determinar la disposición y capacidad de Libia para actuar en contra de Al-Senussi. En cuanto a la posible falta de disposición, rechazó los alegatos de la defensa y confirmó lo señalado por la SCP I, en el sentido de que el Estado libio estaba efectuando un juicio justo e imparcial que garantizaba los derechos procesales del señor Al-Senussi, pese a la falta de comunicación entre el procesado y el defensor y de las circunstancias de seguridad del Estado.

La Sala procedió de la misma manera en relación con la presunta falta de capacidad, al confirmar que el Estado libio podía controlar la situación de seguridad de los jueces, del centro de detención donde se encontraba el señor Al-Senussi y la recolección de pruebas y testimonios, así este no tuviera contacto con su defensa y las condiciones de seguridad del Estado fueran graves.

En consecuencia, la Sala concluyó que la SCP I actuó correctamente al afirmar la inadmisibilidad del caso Al-Senussi, porque se evidenciaban diferencias notables en cuanto al material probatorio y a las circunstancias fácticas del caso Gaddafi, cuya admisibilidad ya había afirmado. ${ }^{5}$

5 SALA APELACIONES, Prosecutor us Saif Al-Islam Gaddafi and Abdullah Al-Senussi, decisión sobre la apelación de Abdullah Al-Senussi frente a la decisión de la Sala de Cuestiones Preliminares de Libia en contra de la decisión de la Sala de Cuestiones Preliminares I de 11 de octubre de 2013 titulada "Decisión en la admisibilidad del caso en contra de Al-Senussi”, 24 de julio de 2014, ICC-01/11-01/11-565, párr. 94. 